\title{
COD reduction of textile effluent in three-phase fluidized bed bioreactor using Pseudomonas aureofaciens and Escherichia coli
}

\author{
Dharmesh H. Sur ${ }^{1,2} \cdot$ Mausumi Mukhopadhyay ${ }^{1}$
}

Received: 22 November 2016/ Accepted: 6 February 2017/Published online: 8 June 2017

(C) Springer-Verlag Berlin Heidelberg 2017

\begin{abstract}
This paper investigated the effect of mixed cultures of Pseudomonas aureofaciens and Escherichia coli and air as gas on degradation of chemical oxygen demand (COD) in three-phase inverse fluidized beds (TPIFBs) for textile effluents with initial COD of $1200 \mathrm{ppm}$ (effluent 1) and $640 \mathrm{ppm}$ (effluent 2). Investigators focused on the importance of different design of gas spargers of the TPIFB for checking its effect on COD reduction performance. For this purpose, four different gas spargers were fabricated for gas flow entry into bioreactor with different $\%$ open area: Gas sparger 1 (18\% open area), sparger $2(10.42 \%$ open area), sparger 3 (8.077\% open area) and sparger 4 (1.53\% open area). These percentage open area decided the amount of gas flow in a unit time in batch studies, which in turn rely mainly on superficial gas velocity. The reduction in COD was measured at two different superficial gas velocity $(0.00343$ and $0.004068 \mathrm{~m} / \mathrm{s})$ and at two ratio of static bed height to diameter $(\mathrm{H} / \mathrm{D})$ of 0.5 and 0.25 in an aerobic mode. Textile effluent 1 resulted in $98.07 \%$ COD reduction with sparger 3 and discharged at $23.14 \mathrm{ppm}$ in $28 \mathrm{~h}$. Textile effluent 2 resulted in $96.5 \%$ COD reduction with sparger 2 and discharged at $22.4 \mathrm{ppm}$ in $22 \mathrm{~h}$. The
\end{abstract}

Electronic supplementary material The online version of this article (doi:10.1007/s13205-017-0771-0) contains supplementary material, which is available to authorized users.

Mausumi Mukhopadhyay

mmu@ched.svnit.ac.in;

mausumi_mukhopadhyay@yahoo.com

1 Department of Chemical Engineering, Sardar Vallabhbhai National Institute of Technology, Surat, Gujarat 395007, India

2 Department of Biotechnology, V. V. P. Engineering College, Rajkot, Gujarat 360005, India resulting COD values of Effluent 1 and effluent 2 were in range of discharge limit and resulted at a low gas velocity of $0.00343 \mathrm{~m} / \mathrm{s}$ and low H/D ratio of 0.25 . The gas holdup correlation was found to be $\varepsilon_{\mathrm{g}}=0.0064 \mathrm{U}_{\mathrm{g}}^{0.98}$.

Keywords Aerobic treatment - Batch process - Gas sparger - Three-phase inverse fluidized bed bioreactor . Textile effluent

\section{Introduction}

Textile industries produce considerable amounts of effluent with high chemical oxygen demand (COD), which is contributed by recalcitrant organics, toxicants, color and salts (Doble and Kumar 2008). The presence of dyes in the effluent poses the biggest problem since they are recalcitrant and toxic. Two percent of dyes produced are discharged directly in the effluent (Doble and Kumar 2008). Alkali or acids from the processing steps of textile manufacturing units contribute to extreme $\mathrm{pH}$ and high salt content. The effluents from textile industries are generally variable in compositions which may not be biodegradable. Textile effluent is diverse because of processes employed and varieties of chemicals employed in each of the processes. It is difficult to assess the effluent characteristics for evaluating the requirements for suitable wastewater treatment. Therefore, it is necessary to understand process operation and character of individual effluents. Characteristics of textile wastewater are reviewed and that indicated the initial COD for effluent from different processes ranges from 800 to $30,000 \mathrm{mg} / \mathrm{mL}$ (Correia et al. 1994). Due to the presence of grease, dirt as well as nutrients from dye bath additives, the wastewater discharged from a dying process in textile industry is high in COD whereas the 
acceptable limits is $250 \mathrm{ppm}$ (Singh 2000). COD is always indicated as pollution loads resulting from each processing operation of various raw materials. Thus, COD removal is needed with more effective treatment.

COD removals from textile effluent are accomplished by many researchers using various types of reactor systems or via different process strategies. Researchers have worked on Pseudomonas spp. (Vimala et al. 2015; Sriram et al. 2013; Blumel et al. 2002), Escherichia coli (Sriram et al. 2013; Vimala et al. 2015) and Bacillus spp. (Shah et al. 2013; Sriram et al. 2013; Blumel et al. 2002) for degradation of textile wastewater in an aerobic mode. Few researchers have worked on anaerobic reactor system (Shin et al. 2011) and found that a high influent dissolved oxygen (DO) concentration have adverse impacts on organic removal efficiency. Farabegoli et al. (2010) have worked with the mix of aerobic-anaerobic sequencing batch reactor system and deduced the fact that the influent COD/dye ratio to be properly selected to provide the electron equivalents needed for the oxidation of dye molecule. Different reactor systems are used to treat textile effluent with different characteristics: like, submerged filtration using nano-membrane (Zheng et al. 2013), Upflow anaerobic sludge bed reactor (UASB) coupled with adsorption process (Conceição et al. 2013), fluidized bed reactor (Su et al. 2011), microbial degradation (Agarry and Ajani 2011), combination of fixed and fluidized bed (Baban et al. 2010), thermolysis (Kumar et al. 2008), ultrafiltration (Dhodapkar et al. 2007) and sequential anaerobic-aerobic treatments (Kapdan et al. 2003) - to name a few. Different reaction criteria for COD removal have also been worked upon, like: ratio of volume of settled bed to bioreactor (Sokol 2003), use of catalyst system (Kumar et al. 2008) with thermolysis and coagulation treatment as well as solid content of influent (Rajasimman and Karthikeyan 2007). Biotreatment of textile wastewater required few potential indigenous microorganisms for biodegradation of COD (Agarry and Ajani 2011). The appropriate combination of physical or chemical methods or specific chemical and biological conditions are demanded for treating textile effluents (Agarry and Ajani 2011; Baban et al. 2010; Dhodapkar et al. 2007; Kapdan et al. 2003).

As discussed above, there are many ways to treat textile effluents. The fluidized bed bioreactor is one of the most effective methods used in effluent treatment (Buffiére and Moletta 1999). Recently, industrial wastewaters have been treated by aerobic biological treatment in three-phase fluidized bed (Haribabu and Sivasubramanian 2014; Sabarunisha Begum and Radha 2014; Sokol 2012; Sokol and Woldeyes 2011; Rajasimman and Karthikeyan 2007; Ochieng et al. 2003). Air stream is bubbled directly into the liquid, creating three phase in the aerobic treatment of wastewater. In a three phase fluidized bed bioreactor, if the low density solid media particles are employed then the process is referred as inverse fluidization where gas phase is introduced counter currently to the liquid phase at the bottom of the reactor and the bed expands downwards (Haribabu and Sivasubramanian 2014; Sokol and Korpal 2006; Nikolov et al. 2000; Comte et al. 1997). The role of solid media particles is to provide large surface area for microbes where they are retained from the growth. There is a formation of biofilm onto which microorganisms retain to digest organic waste (Rajasimman and Karthikeyan 2007; Sokol 2012). Moreover, three-phase inverse fluidized bed bioreactor (TPIFB) offers large specific support surface area, higher gas phase holdup and higher residence time in comparison to conventional fluidized bed. Therefore, the mass transfer coefficient reaches almost two times higher in the TPIFB than conventional fluidized bed (Nikolov and Karamanev 1987). TPIFB is efficient when used for biological aerobic wastewater treatment. It is 15 times more effective than airlift reactor (Nikolov et al. 2000) and preferred over suspended-cell systems (Sokol 2012).

To investigate the effects of textile effluent characteristics on COD removal, two textile effluents with different COD values are taken and four gas spargers are designed. The purpose of the gas sparger of any fluidized bed is to evenly distribute the gas across the bed inlet (Sokol and Korpal 2006; Comte et al. 1997). Each of the gas spargers is characterized by open percentage area that it offers the air (gas phase) to pass through the wastewater (liquid phase). So each sparger controls the quantity of gas to flow at superficial velocity affecting the mass transfer.

Batch studies (only gas flow with no net liquid flow) for three-phase fluidized bed bioreactor in an inverse mode are countable and very few (Comte et al. 1997; Buffiére and Moletta 1999). The work on performance of three-phase inverse fluidized bed bioreactor (TPIFB) in a batch mode is still much far from complete. Therefore, the present work aims to investigate the performance of TPIFB through measurement of COD reduction in a batch mode with four spargers designed to treat two textile effluents. The effects of initial values of COD, effluent characteristics and effects of superficial gas velocities are discussed. Gas holdup correlation is derived.

\section{Materials and methods}

Air (density $=1.2 \mathrm{~kg} / \mathrm{m}^{3}$, viscosity $=0.018 \mathrm{~Pa} \mathrm{~s}$ ), effluent sample and solid media particles (polypropylene, $4 \mathrm{~mm}$ diameter, $723 \mathrm{~kg} / \mathrm{m}^{3}$ density) comprised the three phases in the reactor column. The schematic diagram of three-phase inverse fluidized bed bioreactor for the batch process was given in Fig. 1. This apparatus was fabricated from acrylic column with a diameter of $0.097 \mathrm{~m}$ and height of $1 \mathrm{~m}$. The 
Fig. 1 Schematic diagram of fluidization in inverse mode

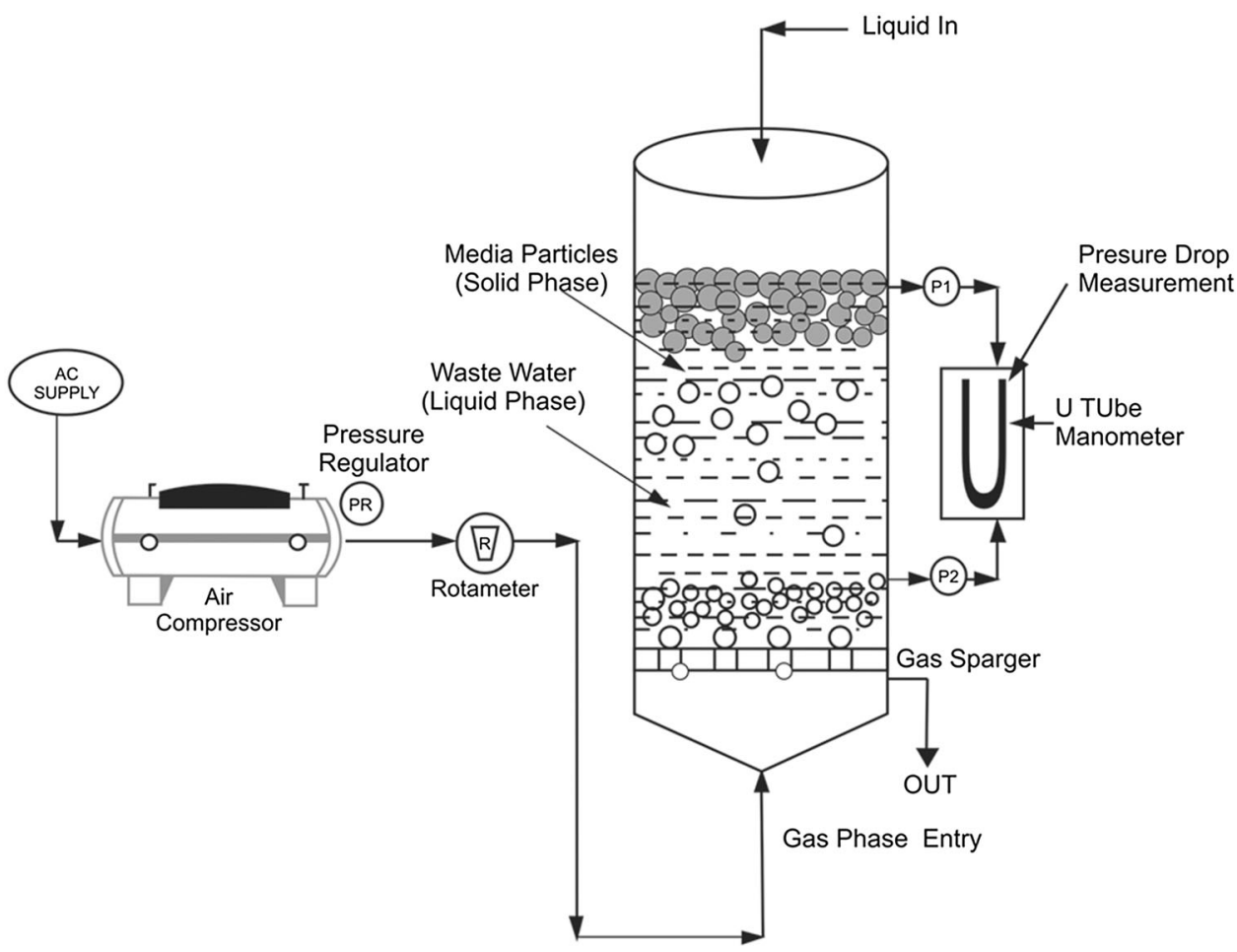

column consisted of liquid entry, sampling point and gas distribution. Synthetic wastewater was added from the top followed by addition of solid media particles. Air compressor was set to make air entry from the bottom. Air entered from the bottom of the reactor through air pressure regulator. Rotameter measured the flow (Online resources: ESM: Figure S1). Sufficient care was taken for the bioreactor operation and that, first the valve of compressor was opened and then valve at the bottom to maintain the required gas flow through the bioreactor. The solid media particles were added in quantities equivalent to the heights of the bioreactor column. This was calculated based on the ratio of static bed height to column diameter (H/D) of 0.5 and 0.25 . Those values were equivalent to 4.85 and $2.43 \mathrm{~cm}$ heights of the particles (static bed height), respectively, in the bioreactor column.

Two raw untreated effluent samples were collected from industrial units in Rajkot district (Gujarat, India) with an initial COD of 1200 ppm (textile effluent 1) and $640 \mathrm{ppm}$ (textile effluent 2). Compositions similar to these industrial effluents were fabricated in the laboratory (Online resources: ESM: Table S1). Major pollutants in textile effluents were characterized by the parameters like $\mathrm{pH}, \mathrm{COD}$, biological oxygen demand (BOD), hardness, $\mathrm{NO}_{2}{ }^{-}$, and total suspended solids (TSS). The characteristics of textile effluents and the fabricated wastewaters were considered for experimental trials. The range of $\mathrm{pH}$ of the effluents were 7.15-8.5 and that of BOD was 107-182.4 (Online resources: ESM: Table S2). The reduction in COD was measured at static liquid conditions and low gas velocities. To facilitate the gas phase entry to the reactor, four different spargers were used. Each of them offered different area by their surface openings. Surface openings were referred as 'percentage openings' or 'open percentage area' in this paper. Percentage open area meant the proportion of open holes $\left(\mathrm{m}^{2}\right)$ over the total surface of gas spargers. These were calculated to be $18 \%$ (sparger 1), $10.42 \%$ (sparger 2), $8.077 \%$ (sparger 3) and $1.53 \%$ (sparger 4). Each of the spargers was checked for its contribution in COD reduction since each of them allowed different volume in unit time to enter the bioreactor. Rotameter and pressure regulators were auxiliaries to this bioreactor column. The microbial cultures were added to the effluent for its degradation. Five different cultures of $P$. putida (NCIM 2872), P. aureofaciens (NCIM 2026), P. fluorescens (NCIM 2174), B. subtilis (NCIM 5433) and E. coli (NCIM 2805) were purchased from National Chemical Laboratory, Pune, India. The COD degradation capability of each of these cultures was determined. Finally, two microbial cultures of $E$. coli (NCIM 2805) and P. aureofaciens (NCIM 2026) were selected due to their higher degradation capabilities for further experimentation. These inoculated cultures were used for the entire bioreactor operation in a batch mode for three different sizes of inoculum-5, 10 and $20 \%$ of the working volume of the reactor. Batch process offered an advantage of sterility and easy handling. The bioreactor was ensured for sterility by two ways; firstly, by the use of air filter before the entry of air into the 
bioreactor from compressor and secondly, by cleaning the media particles by acid solution $(10 \% \mathrm{HCl})$ before adding into the bioreactor. Then the top of the reactor column was closed. The bioreactor was also washed with distilled water and $10 \% \mathrm{HCl}$ solution after each batch.

The experiments were carried out at all possible combinations of parameters including gas velocities $(0.006$, 0.004068 and $0.00343 \mathrm{~m} / \mathrm{s})$, bed heights $(0.3,0.6$ and $0.9 \mathrm{~m}$ ) and the H/D of 0.5 and 0.25 . When the bioreactor operation began, gas bubbles entered the bioreactor through gas sparger. These bubbles were moving in different fashions developing flow patterns including inversion of bed where particles moved downward. This inversion was captured in camera through a series of steps in sequence and presented here (Online resources: ESM: Figure S2). These process sequences occurred for all four gas spargers. The details of these gas spargers are given in Table 1 and Fig. 2.

Pressure taps were mounted at a distance of $0.05 \mathrm{~m}$ from the top, $0.05 \mathrm{~m}$ from the bottom and in the middle of the reactor column for the measurement of pressure through manometer. It was useful in maintaining steady state. At a time, bed of solid media became steady and expansion of bed remained constant. This referred the condition of steady state after which COD removal was observed in batch mode. Very low gas velocities were characteristics of this experimental setup.

\section{Results and discussions}

Textile effluent 1 and textile effluent 2 were treated with liquid at zero velocity and particles remained "fluidized" with only gas flow in TPIFB. Air was sparged from the bottom of the bioreactor. The bioreactor operated at the minimum fluidization velocity of $0.002141 \mathrm{~m} / \mathrm{s}$. The gas flow was increased slowly in the reactor to ensure the inversion whereby the solid media particles moved downwards. Uniform size bubbles mainly contributed the bioreactor operation. After a certain time, bed of solid media became steady with expansion of bed and then remained constant. Initially all the experimentations were accomplished at gas velocities of 0.004068 and $0.00343 \mathrm{~m} /$ $\mathrm{s}$ and at the ratio of static bed height to diameter (H/D) of 0.5 and 0.25 . All these experimental trials were taken for $0.3 \mathrm{~m}$ bed height (based on the fact that bed height did not affect the minimum fluidization velocity in the experimental condition).

After raising gas velocities beyond minimum fluidization, the COD measurements were taken at superficial gas velocities of 0.00343 and $0.004068 \mathrm{~m} / \mathrm{s}$ with gas spargers 1, 2, 3 and 4. Bed was shown inversion at 0.00343 and $0.004068 \mathrm{~m} / \mathrm{s}$. There was no significant movement of particles required for the criteria of inversion when bed operated below the gas velocity of $0.00343 \mathrm{~m} / \mathrm{s}$ and above $0.004068 \mathrm{~m} / \mathrm{s}$ gas velocity, there was formation of slugs. Therefore, the readings were taken at these two velocities. The steady state was confirmed by noting the steady pressure drop. Time taken to reach steady state was about $14 \mathrm{~min}$. At steady state, the readings were taken in batch mode at regular interval time of $2 \mathrm{~h}$ each. The refinements to the time interval were for $10 \mathrm{~min}$.

Initial trials in the bioreactor were conducted using the microbial cultures of $P$. putida (NCIM 2872), P. aureofaciens (NCIM 2026), P. fluorescens (NCIM 2174), B. subtilis (NCIM 5433), and E. coli (NCIM 2805) to investigate their COD reduction capacity (Online resources: ESM: Table S3). The higher COD reduction capacity was exhibited by $P$. aureofaciens (NCIM 2026) and E. coli (NCIM 2805) and, therefore, they were selected for COD reduction across all the experimentations further.

\section{Flow patterns in bioreactor operation}

The bed was completely in packed condition initially. Gas was injected into the bioreactor apparatus with static liquid. Entire bed was fluidized and minimum fluidization velocity attained. Then superficial gas velocity was required to keep the particles in motion. The process resulted in homogeneous bed expansion. Bed had downward movements and it expanded up to the gas sparger. There was no movement past the gas sparger. At the onset of inverse fluidization

Table 1 Specifications for various gas spargers

\begin{tabular}{|c|c|c|c|c|}
\hline $\begin{array}{l}\text { Gas } \\
\text { distributor }\end{array}$ & Description & $\begin{array}{l}\text { Total Area } \\
\left(\mathrm{cm}^{2}\right)\end{array}$ & $\begin{array}{l}\text { Sparger open } \\
\text { area }\left(\mathrm{cm}^{2}\right)\end{array}$ & $\begin{array}{l}\text { Open area } \\
\text { in }(\%)\end{array}$ \\
\hline Sparger 1 & 271 holes, $2.5 \mathrm{~mm}$ diameter each arranged in triangular pitch & 73.86 & 13.279 & 18 \\
\hline Sparger 2 & $\begin{array}{l}180 \text { holes in total: } 36 \text { holes of } 3 \mathrm{~mm} \text { diameter, } 36 \text { holes of } 2.5 \mathrm{~mm} \\
\text { diameter, } 108 \text { holes of } 2 \mathrm{~mm} \text { diameter, arranged at } 10^{\circ} \text { angle }\end{array}$ & 73.86 & 7.6986 & 10.42 \\
\hline Sparger 3 & 190 holes, $2 \mathrm{~mm}$ diameter each. Arranged at $15^{\circ}$ angle & 73.86 & 5.966 & 8.077 \\
\hline Sparger 4 & 39 holes, $2 \mathrm{~mm}$ diameter each at $90^{\circ}$ angle & 73.86 & 1.2246 & 1.53 \\
\hline
\end{tabular}


Fig. 2 Designs of different gas spargers with specifications mentioned in Table 1 a
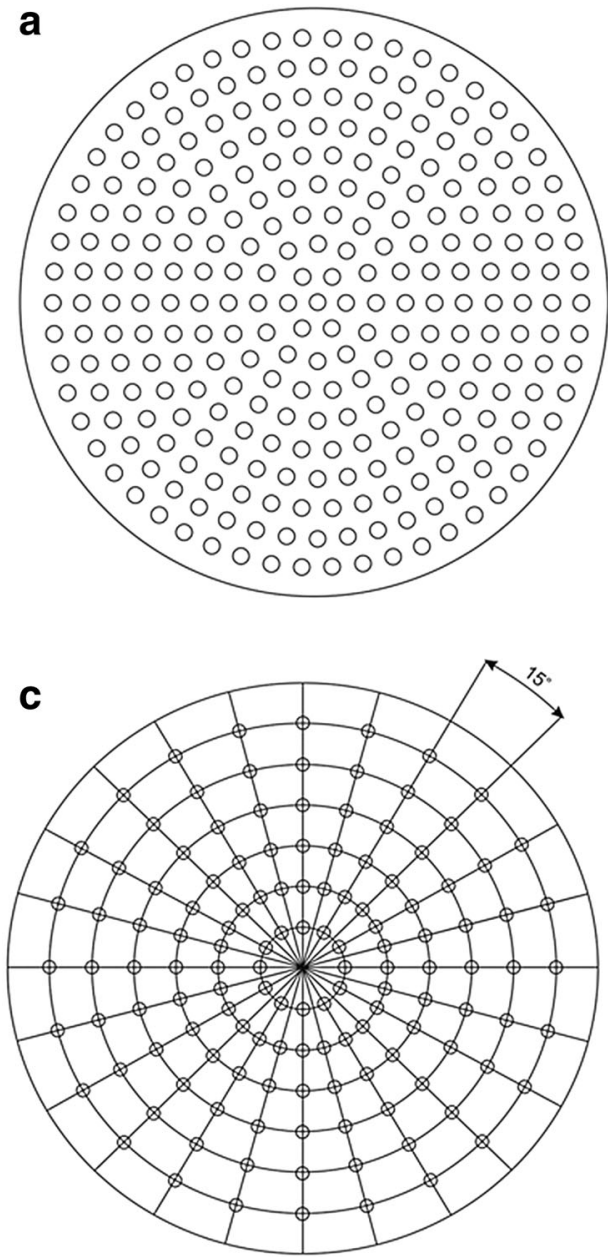

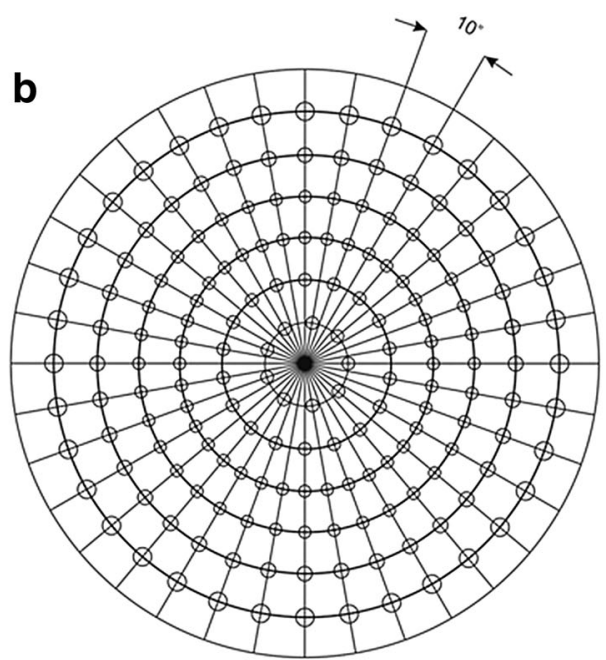

d

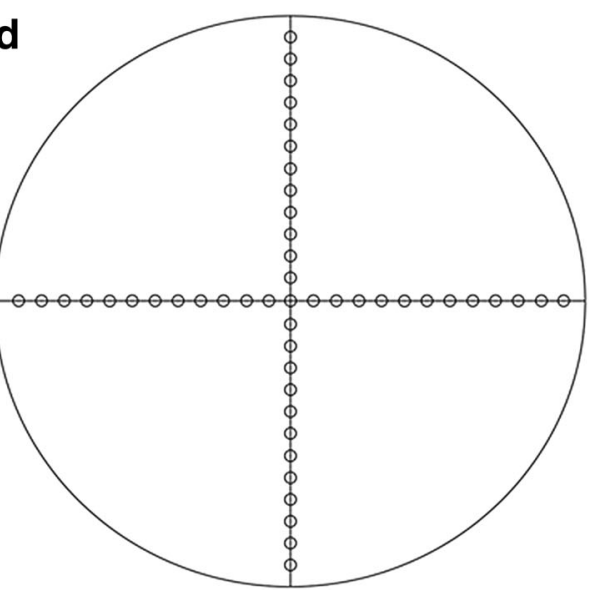

bubble started forming at superficial gas velocity and zero liquid velocity. The interaction between microbial cells and gas bubbles were governed by the flow patterns and it helped in understanding the extent of COD removal through all the four spargers. The flow patterns were influenced by sparger designs since each sparger allowed different volumes of gas into the bioreactor in a unit time. Initially, the flow represented dispersed regime with partially fluidized bed, for all the spargers. Homogeneous and consistent bubble flow was the main characteristics of sparger 2 and 3. However, there was a formation of slugs with the sparger 1 (higher open area) and sparger 4 (lower open area). These slugs were formed from homogeneous bubbly flow existing initially in the bioreactor. Later, the flow pattern indicated the bubbling fluidizing regime as the gas velocity was increased further. Bigger bubbles contributed in reduction of the surface area of interaction between microbes and bubbles. COD reduction dependence on open percentage area of the spargers, effluent characteristics, inoculum size and initial COD value were discussed further.

\section{Effects of open percentage area}

The characteristic design of each of the spargers offer different volumes of gas passing in TPIFB. Since the openings of gas spargers were different, they passed different volume of gas in the TPIFB. The effect of sparger openings were of interest from point of view of aeration. The aeration governed the growth of microorganisms. These microorganisms grew based on oxygen available at a time and degrade the organic pollutants as measured by COD. Their growth decided the reduction of COD for definite batch periods. Therefore, in turn, the gas sparger openings controlled the COD reduction rate. Four spargers were designed specifically with unique percentage open area (openings). The variations in designs of gas spargers were based on percentage open area (openings). So, the effects of these variations of designs of gas spargers were investigated in the performance of TPIFB for textile effluents of different nature.

Once the bioreactor was in steady operating conditions, bubbles formed in consistent patterns. Out of four designs 
of spargers, Sparger 1 (Fig. 3a, b) was the one which had the highest opening area for gas to flow through the two phases- liquid effluent and solid media particles. Sparger 1 exhibited mainly bubble flow in case of textile effluent 1 and textile effluent 2 . In the initial phase of the bioreactor operation, $E$. coli and $P$. aureofaciens mixed culture adopted to the chemical environment of the effluents in the period between 12 and $25 \mathrm{~h}$ for effluent 1 and between 8 and $17 \mathrm{~h}$ for effluent 2 . These periods showed consistent growth of this mixed culture. The microorganisms retained on the surface of polypropylene particles to degrade textile effluent and were responsible for COD reduction. Turbidity was observed for these periods due to growth of $E$. coli and $P$. aureofaciens. Then after, there was no significant changes in COD reduction for effluent 1 and effluent 2, i.e., after $12 \mathrm{~h}$ for effluent 1 (Fig. 3a) and after $8 \mathrm{~h}$ for effluent 2 (Fig. 3b). Once this phase was over, gas holdup exhibited in the bioreactor column and created few slugs. Slug formation was not favorable for the growth of $E$. coli and $P$. aureofaciens. These slugs, as bigger irregular volumes of gas bubbles, were generated from smaller bubbles. Bigger bubbles contributed in reduction of the surface area of interaction between microbes and bubbles. This resulted in slower reduction of COD after $25 \mathrm{~h}$ for effluent 1 and after $17 \mathrm{~h}$ for effluent 2. Maximum removal efficiency achieved in sparger 1 was $88.3 \%$ at H/D of 0.5 with gas velocity of $0.00343 \mathrm{~m} / \mathrm{s}$ for effluent 1 . For effluent 2, maximum COD removal efficiency achieved was $81 \%$ at H/D of 0.25 and gas velocity of $0.00343 \mathrm{~m} / \mathrm{s}$ with sparger 1 . Both of these effluents required low gas velocities to achieve the maximum possible COD reduction.

Sparger 2 (Fig. 3c, d) had an open surface area of $10.42 \%$. It exhibited consistent and homogeneous bubbly flow. However, the rate of degradation of COD in case of effluent 2 was little inconsistent between 8 and $16 \mathrm{~h}$ at high superficial gas velocity $(0.004068 \mathrm{~m} / \mathrm{s})$ and H/D of 0.5 . This occurred owing to the presence of steady gas bubbles in comparison to that for effluent 1 at $0.004068 \mathrm{~m} / \mathrm{s}$ gas velocity and thus higher superficial gas velocity was not much desirable. Sparger 2 generated bigger gas bubbles at much faster rate compared to sparger 1 . Hence the effective surface area for mass transfer was reduced for sparger 2 . So, bigger bubbles were avoided by keeping superficial gas velocity as low as possible. The process of COD degradation was then dependent on both-gas velocity and sparger, apart from H/D ratio. Effluent 1 and effluent 2 resulted in $96.5 \%$ reduction in COD. There were consistent bubbles in both the spargers 1 and 2; however, the time taken to reach the value of maximum COD reduction was different since sparger 1 exhibited few slugs as mentioned earlier. This occurred at the gas velocity of $0.00343 \mathrm{~m} / \mathrm{s}$ and $0.25 \mathrm{H} / \mathrm{D}$ for both the effluents. This strengthened the idea of COD degradation with low superficial gas velocity
Fig. 3 COD reduction in Sparger 1 (a, b for effluent 1, 2), Sparger 2 (c, $\mathbf{d}$ for effluent 1,2), Sparger 3 (e, $\mathbf{f}$ for effluent 1,2), Sparger 4 (g, $\mathbf{h}$ for effluent 1,2 ); at $\mathrm{H} / \mathrm{D}$ ratio of 0.5 and 0.25 with gas velocities of 0.004068 and $0.00343 \mathrm{~m} / \mathrm{s}$

and low H/D ratio. Sparger 3 (Fig. 3e, f) was designed for open surface area of $8.077 \%$. The experimental trails on sparger 3 resulted with same trend of flow pattern as that of sparger 2, but with different values of COD removal. Mass transfer occurred for these two spargers in consistent manner with discrete bubbles of air until full batch operation was over. The maximum possible COD reduction with the sparger 3 was $98.07 \%$ (at $0.00343 \mathrm{~m} / \mathrm{s}$ and 0.25 H/D) for textile effluent 1. For effluent 2, it was $94.89 \%$, but at higher gas velocity of $0.004068 \mathrm{~m} / \mathrm{s}$ and higher H/D of 0.5 .

On the other side, Sparger 4 (Fig. 3g, h) was found with the least COD degradation efficiency amongst all four spargers, since it had the least open percentage area which allowed lower quantity of air into the bioreactor column. So gas bubbles required comparatively more time to reach the bottom of the static bed in the bioreactor. Due to this reason, there was consistent mass from sparging point to the bottom of the bed. This sparger generated clear slugs. Slugs formed due to accumulation of bigger bubbles, which in turn resulted from smaller sized gas bubbles. Due to slugging, the mixed culture comprising $E$. coli and $P$. aureofaciens made poor contacts with gas phase which resulted in poor mass transfer. This never happened for other three spargers (sparger 1, 2, 3) discussed earlier. After taking three trials on each of these spargers, it was found that, open percentage area of each of the spargers was an important parameter in deciding reduction of COD of the effluents. Table 2 exhibits the comparison of parameters during experimental trials on textile effluents and fabricated wastewater. It indicated that in most of the cases, low gas velocity together with low H/D ratio was sufficient in reducing COD. In case of sparger 2 and 3, bubbly flow was only responsible for the degradation process and that for sparger 1 was bubbly flow and few slugs. However, sparger 4 was not performing well in comparison with other spargers. All the trials revealed that the overall process of COD degradation was comprised of following phases when bioreactor is in operation: (1) attainment and maintenance of superficial gas velocity (2) adoption of mixed culture of E. coli and $P$. aureofaciens to the bioreactor environment (3) depletion of pollutants from textile effluents through biodegradation by $E$. coli and $P$. aureofaciens. Performance of TPIFB for textile effluent is compared with other effluents for various reactor systems in Table 3 exhibiting the time taken for COD reduction in each case with their respective modes - the batch and the continuous mode. 

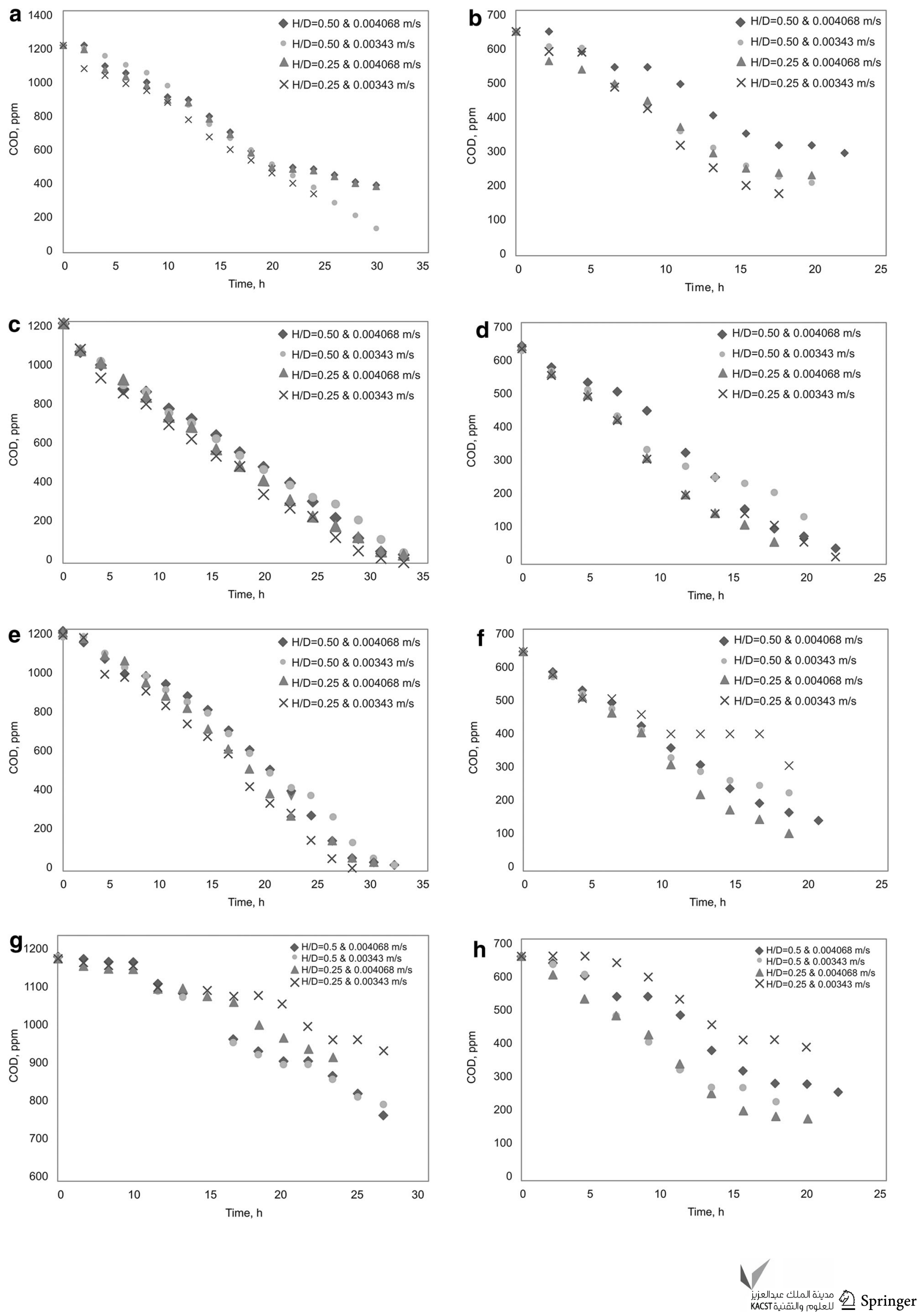
Table 2 Comparison of parameters for trials on textile effluents and fabricated wastewater

\begin{tabular}{|c|c|c|c|c|c|c|c|c|c|c|c|c|c|c|c|c|}
\hline \multirow[t]{2}{*}{ Sparger } & \multicolumn{4}{|c|}{ Max COD reduction (\%) } & \multicolumn{4}{|c|}{ Time taken $(\mathrm{h})$} & \multicolumn{4}{|c|}{ Gas velocity $(\mathrm{m} / \mathrm{s})$} & \multicolumn{4}{|c|}{$\mathrm{H} / \mathrm{D}$ ratio } \\
\hline & E1 & FE1 & E2 & FE2 & E1 & FE1 & E2 & FE2 & E1 & FE1 & E2 & FE2 & E1 & FE1 & E2 & FE2 \\
\hline 1 & 88.30 & 98.16 & 81.00 & 93.00 & 30.00 & 8.00 & 16.00 & 34.00 & 0.00343 & 0.004068 & 0.00343 & 0.004068 & 0.5 & 0.25 & 0.25 & 0.5 \\
\hline 2 & 96.50 & 99.50 & 96.50 & 96.95 & 28.70 & 6.80 & 22.00 & 32.00 & 0.00343 & 0.004068 & 0.00343 & 0.00343 & 0.25 & 0.5 & 0.25 & 0.25 \\
\hline 3 & 98.07 & 98.50 & 94.89 & 96.70 & 28.00 & 6.80 & 20.00 & 34.00 & 0.00343 & 0.004068 & 0.004068 & 0.00343 & 0.25 & 0.5 & 0.5 & 0.25 \\
\hline 4 & 39.93 & 96.16 & 72.12 & 92.20 & 27.80 & 7.00 & 18.00 & 38.00 & 0.004068 & 0.004068 & 0.00343 & 0.004068 & 0.5 & 0.25 & 0.5 & 0.5 \\
\hline
\end{tabular}

$E 1$ effluent 1, E2 effluent 2, FE 1 fabricated effluent $1, F E 2$ fabricated effluent 2

\section{Effect of effluent characteristics}

Textile effluent 1 and textile effluent 2 were experimented with different gas velocities, H/D ratio and open area of spargers. The effluent 1 resulted in $98.07 \%$ reduction with final value of COD as $23.18 \mathrm{ppm}$. The effluent 2 resulted in $96.5 \%$ reduction reaching at $22.4 \mathrm{ppm}$ with sparger 2 . Both the textile effluents met the discharge standards. The time taken for maximum COD reduction by effluent 1 and effluent 2 were different and the difference in the reduction of COD was comparatively low. It meant that the mixed culture of E. coli and $P$. aureofaciens species degraded COD of textile effluents taking different time based on their initial values. Therefore, initial value of these pollutants load (COD) also played a role in achieving final value. Reduction in these pollutants was the first strategy in prevention of pollution. High amount of TSS was the indication of high turbidity. High turbidity was observed in case of sparger 1 with assisted slugs and resulted in lowering COD. So, high turbidity was not preferred for better reduction in COD through growth of $E$. coli and $P$. aureofaciens. Other important parameters generally found in most of the textile effluents are $\mathrm{NO}_{2}{ }^{-}$and BOD. They did not influence the degradation in COD that occurred by the cultures of E. coli and $P$. aureofaciens in TPIFB. Characterization and subsequent treatment of textile effluents 1 and 2 using E. coli and P. aureofaciens enhanced the performance of the treatment of textile effluent 1 and textile effluent 2 in TPIFB.

\section{Effect of inoculums size}

The growth rate of bacteria controlled the oxygen demand and hence, affected the COD reduction. For initial trials, three different inoculum size (volume) were taken as 5,10 and $20 \%$ of the wastewater for COD degradation (Online resources: ESM: Table S4a and S4b). For all the volumes of the inoculum, mostly lower gas velocity imparted higher COD reductions, using $P$. aureofaciens and E. coli, for both effluent 1 and effluent 2 . The visual observation revealed dominance of slugs and more turbidity in the bioreactor when $20 \%$ inoculum size was used. Since the slugs contributed insufficient phase contacts between gas and liquid phases, the COD reduction was lowered. This effect was enhanced by turbidity due to overgrown cultures with $20 \%$ inoculum size of $P$. aureofaciens and $E$. coli and these two conditions were undesirable. Trials with $5 \%$ inoculum volume size resulted with more COD reduction in comparisons to that of $20 \%$ inoculum volume. Very less amount of turbidity was observed at 5\% inoculum size. This problem of turbidity and slugs was eliminated when trials were taken with $10 \%$ inoculum size. For both the effluent 1 and the effluent 2, the highest COD reduction was achieved with $10 \%$ inoculum volume. Flow patterns (as discussed in earlier section) were normal ensuring good mass transfer properties in the trials with $10 \%$ inoculum volume and hence this inoculums size was carried on for all the experimentations.

\section{Effects of gas holdup}

Gas hold up increased with increasing gas velocity at zero liquid velocity. The average value of gas holdup was measured based upon the increase in the height of the column by volumetric expansion method. It was calculated as a ratio of difference between final height and initial height to the final height of the bioreactor column. The average values of gas hold up were considered while developing the correlation. Gas holdup correlations from literature for different ranges of gas flow rates are compared in Table 4. The gas holdup values reported here were lower than reported by others. Chisti (1989) operated at much lower gas velocity and obtained $n(0.80)$. At low gas flow rates, there existed almost a linear relation between gas holdup $\left(\varepsilon_{\mathrm{g}}\right)$ and gas velocity $\left(U_{\mathrm{g}}\right)$, as $\varepsilon_{\mathrm{g}}=k U_{\mathrm{g}}^{n}$, given in literature (Ochieng et al. 2003). The gas velocity $(\mathrm{cm} / \mathrm{s})$ was correlated with gas holdup to obtain $n$ and $k$ values. Fluidization was possible with lower gas flow rates in the inverse mode (lower density of solid media particles). The present work confirmed this and proposed the correlation for the gas holdup as below.

$\varepsilon_{\mathrm{g}}=0.0064 U_{\mathrm{g}}^{0.98}$

Higher value of ' $n$ ' indicated that lower gas velocity was required for the bioreactor operation. The value of ' $n$ ' in 


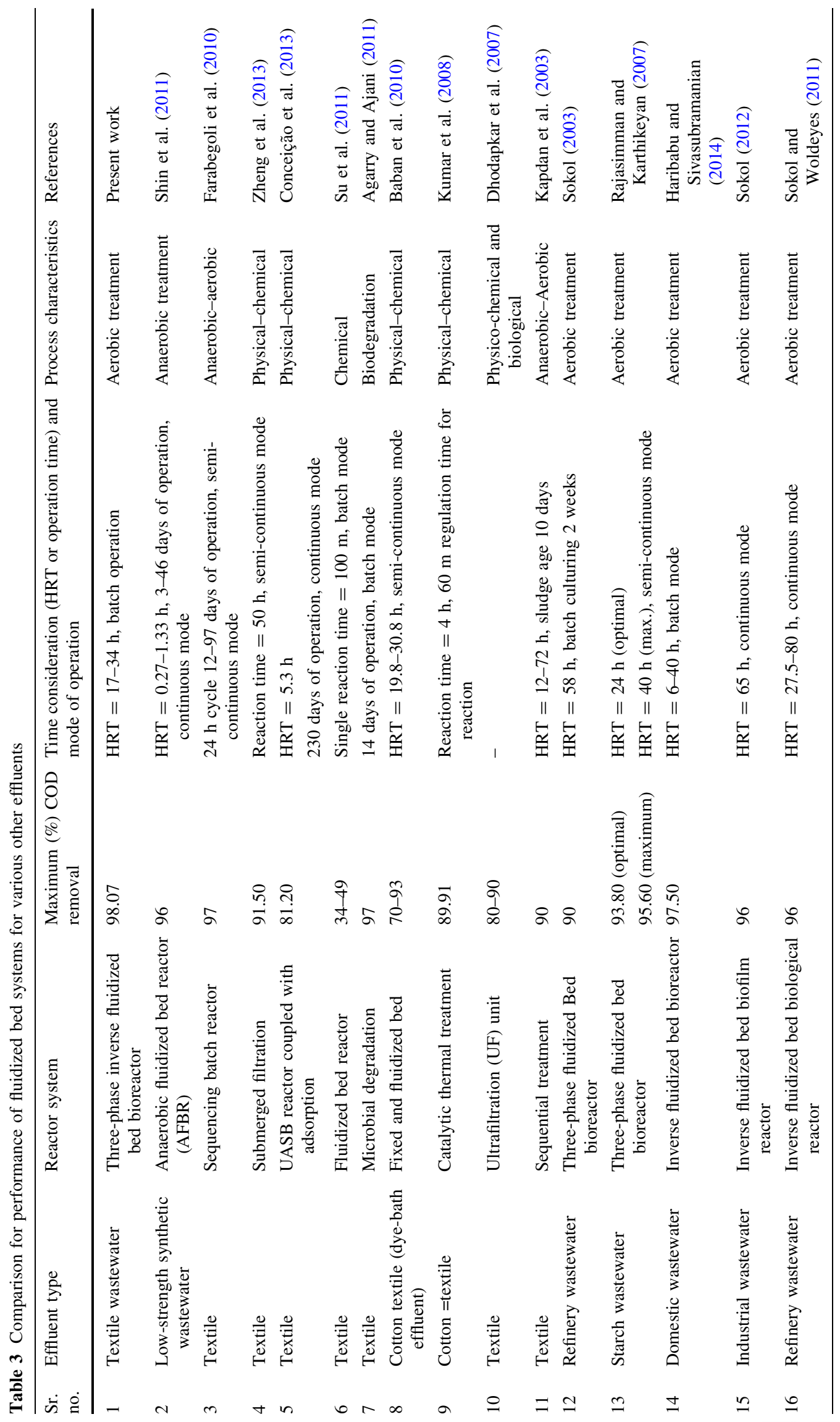


Table 4 Gas holdup correlations

\begin{tabular}{lcccc}
\hline S. no. & $U_{\mathrm{g}}(\mathrm{cm} / \mathrm{s})$ & $\varepsilon_{\mathrm{g}}$ & Correlation & References \\
\hline 1 & $0.34-0.41$ & $0.0078-0.0109$ & $\varepsilon_{\mathrm{g}}=0.00639 U_{\mathrm{g}}^{0.995}$ & Present work \\
2 & $1-8$ & $0.05-0.3$ & $\varepsilon_{\mathrm{g}}=0.71 U_{\mathrm{g}}^{0.535}$ & Ochieng et al. (2003) \\
3 & $0.1-1.8$ & $0.003-0.045$ & $\varepsilon_{\mathrm{g}}=1.45 U_{\mathrm{g}}^{0.8}$ & Chisti (1989) \\
4 & $20-800$ & $0.2-0.9$ & $\varepsilon_{\mathrm{g}}=0.417 U_{\mathrm{g}}^{0.44}$ & Kito et al. (1976) \\
\hline
\end{tabular}

the present work was 0.98. It indicated strict bubble regime.

\section{Effect of initial COD values}

Mixed culture comprising $E$. coli and $P$. aureofaciens consumed more time in adapting to the chemical environment for textile effluent 1 (higher initial values of COD). However, with lower initial values of COD as in textile effluent 2, reduction of COD was achieved in comparatively shorter time.

Higher initial COD indicated higher organics in it. Higher COD required $28 \mathrm{~h}$ to degrade the organics content present for textile effluent 1 with sparger 3 whereas textile effluent 2 degraded maximum possible organics in $22 \mathrm{~h}$ with sparger 2 (both effluents exhibited maximum COD reduction at $H / D$ ratio of 0.25 and $0.00343 \mathrm{~m} / \mathrm{s}$ gas velocity). Adaptability of $E$. coli and $P$. aureofaciens was different for both the effluents. E. coli and $P$. aureofaciens had to adjust to the harsher environment of textile effluent 1 taking more $6 \mathrm{~h}$ to that in comparison with textile effluent 2 for removing maximum COD. However, more the value of initial COD of textile effluent; more duration required for degrading the COD. Organics of effluent 1 degraded over larger duration. Exactly opposite happened for textile effluent 2. Stoichiometry of available and required oxygen via aerobic digestion mode governed COD reduction. The supply of air was constant for textile effluent 1 and textile effluent 2 during the bioreactor operation. Flow regimes remained the similar over a period of degradation for textile effluent 1 and textile effluent 2 and nature of degradation was identical in regard to the growth pattern of E. coli as well as $P$. aureofaciens.

Both of these effluents comprised various nutrients onto which the growth of $E$. coli. and $P$. aureofaciens were dependent. Their growth decided the capacity to degrade the COD contents. Dextrose was the main nutrient for the growth of $E$. coli as well as $P$. aureofaciens. Urea and yeast extract served as nitrogen supplier to these microbial cultures. The composition of fabricated wastewater had typical $\mathrm{pH}$ content between 7 and 9 which was optimal for the growth of $E$. coli and $P$. aureofaciens. This composition mimicked the actual textile effluent as far as the nutrient contents were concerned.

\section{Conclusions}

Textile effluents 1 and 2 reduce COD that it remains within permissible limit $(<250 \mathrm{ppm})$ after treatment. Effluent 1 reduces in COD value from $1200 \mathrm{ppm}$ to $23.14 \mathrm{ppm}$ (98.07\% reduction) with sparger 3 in $28 \mathrm{~h}$. Effluent 2 degrades COD from initial $640 \mathrm{ppm}$ to 22.4 ppm (96.5\% reduction) with sparger 2 in $22 \mathrm{~h}$. Gas spargers play a vital role in COD reduction process. Both samples accomplish maximum COD reduction at low gas velocity of $0.00343 \mathrm{~m} / \mathrm{s}$ and low H/D ratio of 0.25 . TPIFB is an effective bioreactor in treatment of textile effluent.

Acknowledgements This work was supported by the Gujarat Council on Science and Technology, Gandhinagar, India, under its Minor Research Grant [GUJCOST/MRP/12-13/62/1311].

\section{Compliance with ethical standards}

Conflict of interest This manuscript is the authors' original work and has not been published nor has it been submitted simultaneously elsewhere. All authors have checked the manuscript and have agreed to the submission.

\section{References}

Agarry SE, Ajani AO (2011) Evaluation of microbial systems for biotreatment of textile waste effluent in Nigeria: biodecolourization and biodegradation of textile dye. J Appl Sci Environ Manag 15:79-86

Baban A, Yediler A, Avaz G (2010) et al. Biological and oxidative treatment of cotton textile dye-bath effluents by fixed and fluidized bed reactors. Bioresour Technol 101:1147-1152

Blumel S, Knackmuss HJ, Stolz A (2002) Molecular cloning and characterization of the gene coding for the aerobic azoreductase from Xenoplylus azovorans KF46F. Appl Environ Microbiol 68:3948-3955

Buffiere P, Moletta R (1999) Some hydrodynamic characteristics of inverse three phase fluidized-bed reactors. Chem Eng Sci 54:1233-1242

Chisti MY (1989) Air-lift bioreactors. Elsevier, London 
Comte MP, Bastoul D, Hebrard G, Roustan M (1997) Hydrodynamics of a three-phase fluidized bed-the inverse turbulent bed. Chem Eng Sci 52:3971-3977

Conceição V, Freire FB, Carvalho KQ (2013) Treatment of textile effluent containing indigo blue dye by a UASB reactor coupled with pottery clay adsorption. Acta Sci 35:53-58

Correia VM, Stephenson T, Judd SJ (1994) Characterization of textile wastewaters-a review. Environ Technol 15:917-929

Dhodapkar RS, Pophali GR, Nandy T (2007) et al. Exploitation results of seven RO plants for recovery and reuse of treated effluents in textile industries. Desalination 217:291-300

Doble M, Kumar A (2008) Biotreatment of industrial effluents. Butterworth-Heinemann, Noida

Farabegoli G, Chiavola A, Rolle E (2010) et al. Decolorization of reactive red 195 by a mixed culture in an alternating anaerobicaerobic sequencing batch reactor. Biochem Eng J 52:220-226

Haribabu K, Sivasubramanian V (2014) Treatment of wastewater in fluidized bed bioreactor using low density biosupport. Energy Procedia 50:214-221

Kapdan KI, Tekol M, Sengul F (2003) Decolorization of simulated textile wastewater in an anaerobic-aerobic sequential treatment system. Process Biochem 38:1031-1037

Kito M, Shimada M, Sakai T, Sugiyama S, Wen CY (1976) Performance of turbulent bed contactor: gas holdup and interfacial area under liquid stagnant flow. In: Proceedings of international fluid conference on fluid technology, pp 411-429

Kumar P, Prasad B, Mishra IM et al (2008) Decolorization and COD reduction of dyeing wastewater from a cotton textile mill using thermolysis and coagulation. J Hazard Mater 153:635-645

Nikolov LN, Karamanev DG (1987) Experimental study of the inverse fluidized bed biofilm reactor. Can J Chem Eng 65:214-219

Nikolov V, Farag I, Nikov I (2000) Gas-liquid mass transfer in bioreactor with three-phase inverse fluidized bed. Bioprocess Eng 23:427-429

Ochieng A, Odiyo JO, Mutsago M (2003) Biological treatment of mixed industrial wastewaters in a fluidized bed reactor. J Hazard Mater B96:79-90

Rajasimman M, Karthikeyan C (2007) Aerobic digestion of starch wastewater in a fluidized bed bioreactor with low density biomass support. J Hazard Mater 143:82-86
Sabarunisha Begum S, Radha KV (2014) Hydrodynamic behavior of inverse fluidized bed biofilm reactor for phenol biodegradation using Pseudomonas fluorescens. Korean $\mathrm{J}$ Chem Eng 31:436-445

Shah MP, Patel KA, Nair SS, Am Darji (2013) Microbial degradation of textile dye (Remazol Black B) by Bacillus spp. ETL-2012. J Bioremed Biodegrad 4(2):1-5

Shin C, Bae J, Lee E, McCarty PL (2011) Effects of influent DO/COD ratio on the performance of an anaerobic fluidized bed reactor fed low-strength fabricated wastewater. Bioresour Technol 102:9860-9865

Singh RB (2000) Groundwater updates. In: Sato K (ed) Challenges, monitoring and development of groundwater in north India. Springer-verlag, Tokyo, pp 67-72

Sokol W (2003) Treatment of refinery wastewater in a three-phase fluidized bed bio-reactor with a low density bio-mass support. Biochem Eng J 15:1-10

Sokol W (2012) optimal aerations in the inverse fluidized bed biofilm reactor when used in treatment of industrial wastewaters of various strength. Adv Chem Eng Sci 2:384-391

Sokol W, Korpal W (2006) Aerobic treatment of wastewaters in the inverse fluidized bed biofilm reactor. Chem Eng J 118:199-205

Sokol W, Woldeyes B (2011) Evaluation of the inverse fluidized bed biological reactor for treating high-strength industrial wastewaters. Adv Chem Eng Sci 1:239-244

Sriram N, Reetha D, Saranraj P (2013) Biological degradation of reactive dyes by using bacteria isolated from effluent contaminated soil. Middle East J Sci Res 17(12):1695-1700

Su C-C, Pukdee-Asa M, Ratanatamskul C (2011) et al. Effect of operating parameters on decolorization and COD removal of three reactive dyes by Fenton's reagent using fluidized-bed reactor. Desalination 278:211-218

Vimala G, Jeyakumar P, Devi CA, Singh A, Iyer P (2015) Azo dye degrading bacteria from textile effluent. Int J Curr Microbial App Sci 4(7):199-210

Zheng Y, Yu S, Shuai S, Zhou Q et al (2013) Color removal and COD reduction of biologically treated textile effluent through submerged filtration using hollow fiber nanofiltration membrane. Desalination 314:89-95 